\title{
Development and advancement of handmade textiles as a craft and its role in developing the environment and society, preserving the Egyptian artistic cultural identity and reducing unemployment among youth
}

Nashwa Mustafa Naji - Lecturer, Department of Spinning, Weaving and Knitting -

College of Applied Arts - Benha University

\section{Introduction}

The economic conditions that the country is going through at these times are difficult and it is imperative for scientific research to participate to find solutions to economic problems and work to find job opportunities to reduce the unemployment rate. On the original Egyptian artistic heritage that is not matched by artistic heritage in all countries, and also preserving it under the conditions of globalization, which is a deformation of every original art of high cultural and artistic value. The danger of globalization on the national and cultural identity is the abolition of privacy and pluralism, the unification of cultures, and the disappearance of cultural and national borders for each culture So the national identity of the culture of countries ends and then melts into a new global culture that would eliminate the distinction of each culture in exchange for cultural openness, and civilizations are based on two types of arts (high formal arts, folk arts and environmental crafts) and official arts bear the cultural, religious, social and political vision of the state from the point of view and philosophy of its creators Folk arts and traditional environmental crafts carry the pulse and mood of the street man, with his instinct and spontaneous sense, and the embodiment of beliefs and beliefs Hand people through their emotions. And in history, these arts do not stop and do not disappear, but the vessel in which the people empty their aspirations and aspirations, as they are distinguished by their originality in Egyptian history, so we are distinguished by design and innovation for environmental crafts and traditional industries is our way to global uniqueness by exporting our pure Egyptian arts to the world after developing them and preserving the Egyptian national character and returning to Egyptian heritage and national identity by using modern technology supported by local designs from the reality of the Egyptian environment and not by Western designs coming by modernizing heritage and thus we can address 
globalization on the cultural and national identity by blending the past, the future and the present, and melting them into reality.

\section{Research problem:}

The research problem is summarized in the disappearance of the hand-weaving craft as a result of the migration of workers to it, or that working in another craft gradually more, and that this extinction is another reason which is the failure of parents to bequeath the profession to their children, as it happens before, and what also affects the existence of unemployment, or that this craft, as well as other trades, has a material return. Weak and not commensurate with the requirements of the life we live now, such as an increase in the population, prices, or economic conditions that the country is going through. There is also another problem that helped the extinction of this craft, which is the failure to register artistic folklore, which is a document of the Egyptian artistic cultural identity, and therefore it is necessary for those interested in this type of Arts or handicrafts Carrying out in full swing behind the revival of all handicrafts to work on registering heritage in it in the form of handicraft works of art through which we can emphasize the artistic cultural Egyptian identity.

Search portlet:Emphasis on national identity or local distinction to confront the phenomenon of cultural invasion and the threat of globalization on culture and heritage. Thus, we see that we need a new concept that focuses on the power of reason, imagination, or the ability to innovate or control new technology. We also need a new vision for our conditions so that our eyes are directed towards the future.

More than we turn back, but this new vision must be based on a solid base which is (re-creating our local heritage with a cultural concept) and we must start immediately and before it is too late because the cultural invasion can be apparent or disguised at times in disguise, and that of course In order for the invaders to pretend to be friends, then the theory of cultural conquest is based on the invaders looking at their reality through the invader's view of them. Globalization and heritage are badly and effectively bad apart from other harmful effects, but we are interested in this field to talk about the second effect only because it is closely related to a topic search.

The first effect: It is striking the nation state in the economic or political sphere.

The second effect: It is striking the cultural identity of the nation and obliterating the local distinction or heritage of handicrafts and thus reflects on our distinction and global uniqueness. 
Cultural identity is defined by three characteristics (especially time - the privacy of the place - the cultural specificity). If globalization may affect the privacy of time through communications and other weak influence, or if it can also affect the privacy of the place, it cannot affect the cultural privacy of peoples in order to Make them all dissolve into one unit, as they say, because this cultural peculiarity extends for thousands of years, and therefore this fear is not in place. However, we must take that into account.

Environment: It is everything that surrounds, affects and is affected by natural and life elements around and inside the surface of the earth, as well as the things around us or that affect the survival of living organisms on the surface of the earth, which include water, air, soil, minerals, climate, and the organisms themselves.

The environment can be classified into a natural environment and a built environment. The first is that which consists of a group of natural phenomena that man has no involvement in making. Either those constructed are those that are man-made, such as cities, buildings, or dams.

\section{The types of environments are:}

Natural environment: such as air, water or land.

Social environment: It is a set of laws or regulations that govern the internal relationships of individuals as well as political or social institutions or bodies.

Industrial environment: It is man-made, such as villages, cities, farms, factories, or networks.

From this definition, we find that the environment is a real influence on the human being and his behavior, which has its components. It is the product or the human being who is the consumer of all environmental products, their elements and components.

Design: It forms a major link in our economic, social, political or cultural life, as it is a tool of aid for most of these sectors, as it works to achieve their goals by transferring them by transforming them into an influential visual language that works on the principle of communication or communication, including what is awareness, guidance or promotion, through his ability On attraction or influence depending on its facilitation of the process of communicating information, clear and simplified, which enables it to convey the desired message by implanting meaning and action through color elegance and attractive composition. 
Design is defined:as the process of creating an idea in order to produce a product and developing the principle or testing and manufacturing this product. Then the designer must follow a specific design system. Or, the design process itself is an iterative process in which steps are repeated each time in order to improve product design. It is also a creative method carried out by a designer or a group of designers at the request of the recipient, and a group of producers (workers, programmers, etc.) collaborate to implement his material data in order to deliver a specific message or picture of a product to the consumer audience. The term design refers to a number of technical or professional specialties. Which focuses on modern and sophisticated production that matches the consumer's taste and economic capabilities.

\section{Where are we from the phenomenon of globalization?? There are many} questions that are currently being raised to confront the threat of globalization, the most important of which is where are we from the phenomenon of globalization whose current is almost sweeping in front of it many of the peculiarities of peoples (and talking here about Islamic peoples) and to dismantle the national ties to nations, so what are we doing in order to protect ourselves from this terrifying danger in confrontation We must admit that the phenomenon of globalization has become one of the proven facts in its current era in light of the communications and information revolution that has transformed this vast world into a small village open to all directions, and that the threat of globalization does not represent a danger to a particular nation as much He represents him for the Arab and Islamic nation, which prompts us to insist on the inevitability of reviving nationalism, which is no longer just a dream as it was in the past, but has now become, in light of globalization, an inevitable necessity in defense of existence. Mervat Hassan Al-Swaify says that we have no way but to expand the base of knowledge and progress Scientific to enter the future horizons, while we are in the twenty-first century, it is estimated that this evolutionary history in the rights of science and technology will have wide implications for the wealth of nations and their standards of living, a Any call for modernity or the adoption of advanced language and technologies does not mean the desire to call us to ignore our Arab roots or to abandon our national culture and civilization, as the opposite also depends on our ability on the extent to which respect and respect for the national thought that should remain for the Arab world is the shining flame That does not go out, no matter how many events unfold.

\section{Returning to heritage and adhering to the national identity is the way to globalization:}


Archaeological, historical, artistic, social, popular and other references and researches varied when we are exposed to the word (heritage) and its comprehensive interpretation. It has the term "legacy", meaning that which the ancestors left from the predecessor to the back, as this legacy carries history with all its diverse human activity. Sometimes some linguistic dictionaries refer to it as a cultural structure that is characterized by historical and geographical expansion that expresses a set of interrelated cultural elements and features that continue In construction over a relatively long period of time, the word traditional means heritage in archeology, and it also means interest in the traditional daily culture and the accompanying folk culture, which represents the spirit and mood of the people.

\section{Negative effects of globalization:}

It is declared that globalization calls for the whole world to be a small village, and this is a healthy thing because it works to converge ideas and cultures, and this leads to an increase in interaction between people in all parts of the world and works to increase innovations that serve humanity in all aspects of life, as for the danger of globalization, which is something The unannounced is the following:

\section{The danger of globalization on religion:}

Imposing incorrect beliefs and ideas on developing countries or nations in order to believe in the beliefs and ideas adopted by those major countries that advocate and encourage the phenomenon of globalization with the intention of imposing their different cultures on these developing countries as a result of their scientific and economic progress.

\section{The danger of globalization on culture:}

Imposing strange and morally uncommitted cultures on developing countries and obliterating their cultures in order to isolate and impose the cultures of major countries.

\section{The danger of globalization on art:}

Imposing immoral and pornographic arts in art and religion from the great countries in order to neglect the obliteration of the distinctive artistic identity of developing countries as well as trying to erase the history, civilizations and various environmental arts, which leads to the abolition of the cultures and civilizations of developing or weak countries. The intention here of developing or weak countries is most Islamic countries. There were some Arab countries with a high economic situation, but they are considered to be consuming and 
importing countries of different cultures and so on in all aspects of life, which helps ease the cultural, intellectual and religious invasion of them from the countries that call for globalization.

4. Creativity in Applied Arts:Dr. MagdyArafa tried to approach the definition of artistic creativity, so he said (it is the product of two levels of self-innate thinking without communicative symbols and the second adult includes verbal, mathematical, musical and formal communicative symbols) Whatever the researchers' constant disagreement about the definition of art, beauty and artistic creativity, they agree without exception On the other hand, it is a human spiritual need necessary for progress and the continuation of life, and people in one way and another are heading for an aesthetic path that is divided between creative people and gourmets to help spiritual forces within them, so man in turn creates science, morals, political and economic systems, civilization and technological tools.

\section{Stages of artistic creativity in the field of applied arts design:}

Scientists dealt with the stages of artistic creativity by research in terms of psychological or artistic aspects, so you see psychologists when they address the stages of artistic creativity of the designer. As for the experts in art, they focus on the lines of the artistic work itself. Here is an attempt to merge the two directions for more integration of the image on which the stages of creativity of the artwork there are several stages The designer instructs it to reach the stage of artistic creativity after the completion of the design process, which begins with thinking, then the stages of vision, perception and drafting, and then the stages of creativity are:

- The thinking stage: The thought comes first in the design stages as it is the guiding and motivation for the design process.

- The vision stage: It comes as an indication for the designer to start seeing and observing the elements used or the early beginnings of the design, forming the vocabulary and building the necessary formulas for the design process.

- Perception stage: It is the result of linking processes between elements or vocabulary and formulas. This stage results in sensing the relationships between those vocabulary and formulas to accommodate the perception process. 
- The formulation stage: which is the harmonization of vocabulary and elements according to the formative and aesthetic relations between them, and the adaptation of those vocabulary according to the results and data.

- The creativity stage: it comes as a result of choosing one of the multiple solutions, which requires returning to the thinking stage again to choose one of those solutions, and therefore the design process begins with thought, then vision and perception, then the stage of interaction between vision and perception, then the formulation stage, and the design process ends with thinking about the creativity process. Which includes finding solutions through thought, creativity and addition, but Dr. AfafFarag believes that the previous stages can be combined into two basic stages: the first stage, which is the mental perception of artistic work, and the second stage, which is the artistic process.

\section{Transforming artistic creativity, manual skill and innovation into modern and contemporary products:}

We can say that environmental crafts and traditional industries are among the innate creative activities of most people because they were part of the stream of events that happen to them in their daily lives, or that they take place in isolation from the connected reality.

For this life because the products of these societies are characterized by a vitality and character that is unique to them alone in terms of being a direct expression of it, in addition to a great emphasis and interest on his part in functional beauty. The human touch affects especially the atoms of the materials that the craft combine with and thus we witness the transformation of the product with an abstract function into a work of Artistic works, as we find that the common and traded product has become an asset that is acquired and a source of pleasure and joy, because the hand skill in traditional crafts and environmental crafts leads to the instinctive taste of beauty without the conscious desire to seek it. It also requires an understanding of the rules of formation no less accurate than what is required by any work of art in a manner that fulfills the purpose What is desired is, of course, it is not imperative that environmental crafts be linked wholly or partly with traditions, as life does not stop its wheels, just as the means of livelihood change with the change of customs and traditions and the development of life and the accompanying emergence of new relationships and the emergence of new traditions and the evident fact that in this era in which we live and which reached from Technology developments have far-reaching limits and that humanity is 
indispensable for some of these values that environmental crafts pledge to care for and preserve, because manufacturers and crafts lovers Environmentalism is a lot of values and meanings that we need to base ourselves on in our confrontation with any cultural invasion, and so that we do not spread and struggle in the era of globalization.

But we have to make it clear that we were defending handicrafts, because our defense does not necessarily mean that we reject God, our time is calling for an enthusiastic call to return to the method of manual production, as the reality is that there is a relationship between small tools and large machines and the error lies in our inability to appreciate the role of each of them in the field What pertains to it as well is represented in our inability to accept the value of this role, provided that society has the right in spite of that to choose, and at that time God's threat to man is eliminated

\section{Results and Discussion}

1. shape, increase production, as well as increase the quality of the product.

2. Opening new markets locally and internationally that works to increase product marketing, which leads to an increase in production and production centers.

3. Spreading the Egyptian artistic culture by opening many Preserving handicrafts and not extinguishing them through these multiple programs that aim to revive such handicrafts and then emphasize the Egyptian cultural identity and protect all handicrafts in general and the textile craft in particular from the threat of globalization and the invasion of cultures.

4. Reducing the unemployment rate, increasing the number of manpower and creating new job opportunities for youth.

5. An increase in the citizen's economic standard of living, which leads society to the high rate of economic growth.

6. Preserving and emphasizing the Egyptian cultural identity.

7. Raising the efficiency of those working in the craft of manual weaving, working to develop the product in terms of markets around the world.

\section{Conclusion}

1. Expanding the opening of specialized training centers in the various governorates of the Republic. 
2. Spreading the culture of training and raising the efficiency of handicraft workers, which helps to increase textile hand products while maintaining an increase in their quality.

3. Registration of the Egyptian artistic cultural heritage and the various decorations of the arts in different eras, which contributes to emphasizing the Egyptian artistic cultural identity.

4. Opening exhibitions selling handmade textile products and marketing them in the governorates. Each governor contributes to opening a permanent exhibition for the products.

5. Opening international exhibitions through Egyptian trade attaches and cultural advisors in Egyptian embassies abroad, which promotes the product.

6. Work to revive the hand-weaving craft and keep it from disappearing. This results from creating new job opportunities for young people and training them on how to produce manual kilims and other handmade textiles.

Increasing the holding of art exhibitions, which increases the cultural and artistic taste of society

\section{References}

1- Al-Sidis: Globalization and the Third Way - Merit For publication and information - Cairo 1999.

2- Hazem Al-Beblawi: Dialogue of Egypt and Civilizations (Impressions not specialized) - Thesis was discussed at the Third National Forum for Arts of the Supreme Council of Culture - March 1998.

3- Suleiman Mahmoud Hassan: The Popular Crafts - Master Thesis - Faculty of Art Education - Helwan University -1973

4- - Tariq Ahmed Ibrahim: Creating an application method for non-extended wefts to achieve innovative designs for contemporary kilims with engineering units - Master Thesis - College of Applied Arts Helwan University 1996.

5- Tariq Abd al-Rahman Ahmad: Inspired by folk art designs for use in floor furnishings - a field study in the area of Kufr al-Sheikh - a master's thesis - College of Applied Arts - Helwan University 1996.

6- Afaf Ahmadfarraj: The Psychology of Artistic Appreciation - The Anglo-Egyptian Library, 1999.

7- Handbook: (Seminar of the Social Fund for Development - Small Enterprise Development Agency) Egyptian traditional industries as a comparative advantage in facing global economic changes 2001.

8- Handbook: (Environmental, automatic and traditional crafts) Ministry of Culture - General Authority for Cultural Palaces - General Administration of Plastic Arts and Environmental Crafts 1996.

9- Handbook: (The First International Symposium on Arts and Decoration in Crafts of the Islamic World, Manual) Program for the Development of Handicrafts in the Islamic World - Damascus 1997 AD Research Center for History, Arts and Islamic Culture - Istanbul.

10- Muhammad Ibrahim Mabrouk: Islam and Globalization (a symposium that a group of scholars and thinkers participated in) The Arab National House in 1999.

In this research, the researcher shed light on the economic conditions that the country is going through at this time, and then through scientific research she sheds light on the environment and its inspirations for the designer. She also emphasized the employment of various Egyptian arts in designs that work to 
revive culture and arts and emphasize the Egyptian cultural identity. By registering these artistic motifs from different eras in the form of artworks and hand-woven products that work to record this heritage.

The research also shed light on the disappearance of some handicrafts and the re-raising of their efficiency and the efficiency of those who work in them and work to market the resulting products to open new markets and work to increase the workforce and reduce the unemployment rate among young people because these crafts are almost small enterprises and their cost is not high in their establishment, which leads to attracting Many young people work with it, which brings material benefit to the individual and society, which works to develop and increase the growth of the economy through marketing and the high profitability of the product of selling these products.

The research also shed light on providing exhibitions of products at home and abroad through

Different governorates, in general, or in particular, for tourism, as well as marketing products through exhibitions held through

The commercial attache or Egyptian cultural advisor in all Egyptian embassies in all countries of the world, which leads

To bring about a large number of production agreements, due to the aesthetic value of the hand-made handicraft or the Egyptian motifs

And high technical and material value also to the foreign consumer. 